\title{
Educação a distância e as novas demandas ocupacionais
}

\section{Distance education and the new ocupational demands}

\author{
Daniela Melaré Vieira Barros*
}

\begin{abstract}
RESUMO
Com a nova dinâmica da sociedade da informação e do conhecimento, que privilegia a formação de recursos humanos, nos deparamos com duas análises primordiais: a democratização do processo educativo para a formação de cidadãos e a preparação para o mundo do trabalho. Portanto, neste trabalho, procuraremos discutir as tendências educacionais especialmente a educação a distância como um dos caminhos para a solução de qualificação da sociedade da informação para o mundo do trabalho, caracterizado enquanto demandas de ocupação e suas novas exigências.

Palavras-chave: educação a distância, demandas ocupacionais, mundo do trabalho.
\end{abstract}

\begin{abstract}
Due to the new dynamic of the information society and knowledge which favors the development of human resources, we find two central analysis: the democratization of the educational process in order to develop citizens and to prepare them for the job market. However, we will try to discuss educational trends in this study, especially distance education as a information society solution for qualifying workers for the job market, described as occupational demands and their new requirements.

Key-words: distance education, occupational demands, job market.

* Professora do Centro de Filosofia e Ciências Humanas da Universidade do Sagrado Coração em Bauru, Professora do Departamento de Educação - Unesp - Bauru, doutoranda em Educação Escolar - Unesp, campus de Araraquara. E-mail: dmelare@ fc.unesp.br
\end{abstract}




\section{Educação a distância}

Na sociedade da informação e do conhecimento todas as definições expressas sobre o que seja educação a distância trazem diversas formas de relação entre tecnologia, educação, processo ensino e aprendizagem e ação docente, num determinado tempo e espaço diferenciados.

Quando falamos em educação a distância, (EAD) não imaginamos a gama de características e significados que englobam essas palavras. Ressaltamos as principais tais como: tecnologia educacional, teleducação e educação aberta. Todas estão relacionadas à educação a distância, mas têm significados diferenciados que devem ser esclarecidos para melhor compreensão.

Tecnologia educacional, segundo FROMM (1998, p. 30):

É um processo integrado complexo, que envolve pessoas, procedimentos, idéias, recurso e organização para analisar problemas e planejar, implementar, avaliar e gerir soluções para esses problemas, envolvidos em todos os aspectos da aprendizagem humana [...] a tecnologia educacional abrange três aspectos básicos: recursos destinados à aprendizagem, funções de gestão educacional e funções de desenvolvimento educacional.

A tecnologia educacional compreende a relação das tecnologias e o processo educacional e a educação a distância está inserida neste processo. Já a teleducação utiliza meios eletrônicos para formar e informar, de modo permanente e tendencialmente a distância. Por sua vez, a educação aberta é definida em FIDALGO e MACHADO (2000, p. 119) como:

Processo educativo que implica a ausência de barreiras que limitam o acesso ao ensino superior ou a outros graus de escolarização, seja em termos de requisitos de qualificações prévias, seja quanto à determinação de lugares e tempos determinados para os alunos freqüentarem as aulas. 
Fidalgo e Machado definem a educação aberta numa perspectiva de acesso igualitário e muito mais amplo do que a própria educação a distância. Entendemos, portanto, que a educação a distância está inserida no processo de educação aberta.

As reflexões de BATES (1995), que trabalha com a área de tecnologias e educação na University of Britich Columbia do Canadá, trazem a diferença entre educação aberta e educação a distância:

Open Learning is primarily a goal, or an educacional policy: the prevision of learning in a flexible manner, built around the geographical, social and time constraints of individual learners, rather than those of an educational institution.

Distance Education is one means to that end: it is one way by which learners can study in a flexible manner, by studying at a distance from the originator of the teaching material: students can study at their own time, at the place of their choice (home, work or learning centre), and without face-to-face contact with the teacher. ${ }^{1}$ (BATES, 1995, p. 27)

A educação aberta, segundo BATES (1995), abrange uma condição de política educacional do país; a educação a distância seria uma das metas implícitas para concretizar o que se denomina educação aberta.

Em relação à teleducação, há autores que a definem como educação a distância. Bordenave ao explicar a sinonímia entre os dois termos diz que:

Teleducação vem de telos que em Grego significa distância [...]. Não significa apenas educação por televisão, como muitos pensam, mas qualquer forma mediatizada na educação, isto é, onde o contato entre professor e aluno é feito pela intermediação de um ou de vários meios de comunicação. (BORDENAVE, 1987, p. 13)

1 A aprendizagem aberta é principalmente uma meta ou uma política educacional: a previsão de aprendizagem em um modo flexível, construído em torno do constrangimento de tempo, social e geográfico de aprendizes individuais, ao contrário dos aprendizes de uma instituição educacional. A educação a distância é um meio para este fim: ela é uma maneira pela qual os aprendizes podem estudar em um modo flexível, estudando a distância do material de ensino originário: os alunos podem estudar no seu próprio tempo, no lugar que desejarem (em casa, no trabalho ou centro de aprendizagem), e sem o contato cara-a-cara com o professor. 
Ainda em Bordenave, as características em teleducação são descritas enquanto:

...uma organização de ensino e aprendizagem na qual estudantes de variadas idades e antecedentes estudam em grupos e/ou individualmente em seus lares ou lugares de trabalho com materiais auto-instrucionais produzidos centralmente, distribuídos através de uma variedade de meios e com comunicação regular e re-alimentação entre estudantes e professores. (BORDENAVE, 1987, p.13)

Na definição expressa em FIDALGO e MACHADO (2000, p. 118):

Os termos teleducação e telensino são utilizados para expressar o mesmo processo, pois tele vem do grego, que significa distância. A educação a distância (EAD) é um modelo educativo, que pode ser organizado de modo a possibilitar ao aluno fazer a reconstrução do conhecimento através de sua própria experiência. Ela acontece mediante a separação física entre os atores do processo de aprendizagem (professor e aluno) porém, estabelecendo uma relação de comunicação e aprendizagem multidirecional. Em geral vem ocorrendo através do uso de novas tecnologias, mais precisamente da internet e tem como finalidade vencer a distância física, possibilitando o acesso à educação a um maior número de pessoas, sendo uma importante estratégia de formação. A EAD deve preocupar-se, principalmente, com os aspectos pedagógicos envolvidos na utilização das tecnologias e na construção da aprendizagem, não podendo estar desvinculada do sistema educacional visto como totalidade. A educação a distância pressupõe, também a possibilidade de encontros ocasionais com propósitos didáticos e de socialização.

As discussões conceituais realizadas trouxeram diferenças sobre os termos, mas o que se deve deixar claro nas afirmações é que a tecnologia educacional, a educação aberta e a teleducação fazem parte de uma só relação da educação e do progresso tecnológico, sendo este um auxiliador espacial, temporal e informacional na fluência dos processos de ensino e aprendizagem.

Em relação ao conceito de educação a distância, as diferenças estão presentes na terminologia educação e ensino a distância. 
Costumam-se utilizar os termos indistintamente, mas é importante ressaltar uma pequena diferença entre eles: o ensino caracteriza-se pela instrução, transmissão de conhecimentos e informações, adestramento, treinamento; já a educação é um processo ensino-aprendizagem que leva o indivíduo a aprender a apreender, a saber pensar, criar, inovar, construir conhecimentos, participar ativamente de seu próprio crescimento. É um processo de humanização que alcança o pessoal e o estrutural, partindo da situação concreta em que se dá a ação educativa numa relação dialógica. Para melhor entendermos as argumentações que deram origem às diferenças dos conceitos, temos algumas definições em BELLONI (1999, p. 25):

Ensino a distância é o ensino que não implica a presença física do professor indicado para ministrá-lo no lugar onde é recebido, ou no qual o professor está presente apenas em certas ocasiões ou para determinadas tarefas (Lei Francesa, 1971).

Educação a distância pode ser definida como a família de métodos instrucionais nos quais os comportamentos de ensino são executados em separado dos comportamentos de aprendizagem, incluindo aqueles que numa situação presencial seriam desempenhados na presença do aprendente de modo que a comunicação entre o professor e o aprendente deve ser facilitada por dispositivos impressos, eletrônicos, mecânicos e outros.

A definição de NISKIER (1999, p. 50) apoia-se nos aspectos diferenciados referentes à educação a distância, tanto nas questões metodológicas como no planejamento do processo ensino e aprendizagem utilizando tecnologias.

...educação a distância é a aprendizagem planejada que geralmente ocorre num local diferente do ensino e, por causa disso, requer técnicas especiais de desenho de curso, técnicas especiais de instrução, métodos especiais de comunicação através da eletrônica e outras tecnologias, bem como arranjos essenciais organizacionais e administrativos.

Para NETTO (1998), o termo é educação a distância porque os termos teleducação e telensino são também assemelhados e caracterizam-se por pro- 
fessores e alunos encontrarem-se em lugares distintos. Sua perspectiva é somente uma diferenciação de espaço, mas a relação é a mesma e por isso a define como educação a distância.

A definição proposta por ELY apud NETTO (1998, p. 47)esclarece que:

...educação a distância refere-se a ensino e aprendizagem em circunstâncias nas quais o professor e o aprendiz estão separados um do outro no tempo e no espaço; inclui Telecursos, estudos por correspondência, ensino-aprendizagem por meio de computador como parte de um sistema abrangente de educação ou treinamento que culmina com a complementação de uma tarefa, curso, currículo ou programa de treinamento.

As caracterizações dessa definição ressaltam a abrangência de uma modalidade de educação. Neste aspecto, a educação a distância não se define enquanto uma modalidade sistematizada, mas uma ferramenta por si só.

De acordo com CHERMANN e BONINI (2000, p. 16), numa perspectiva de igualdade dos termos ensino e educação, observamos:

...educação/ensino a distância é um método racional de partilhar conhecimentos, habilidades e atitudes através da aplicação da divisão de trabalho e de princípios organizacionais, tanto quanto pelo uso extensivo de meios de comunicação, especialmente para o propósito de reproduzir materiais técnicos de alta qualidade, os quais tornam possível instruir um grande número de estudantes. Ao mesmo tempo, enquanto esses materiais durarem é uma forma industrializada de ensinar e aprender.

CHERMANN e BONINI (2000) expressam em suas argumentações um trabalho conjunto entre tecnologia e estudo para um determinado fim: a produção do conhecimento, mas como eles mesmos citam, uma forma industrializada de ensinar e aprender. A verdadeira EAD não pode deixar os princípios educativos perderem-se na perspectiva de produção e industrialização do conhecimento, caracterizada por não relacionar os conhecimentos científicos aos aspectos políticos e sociais da sociedade. 
Na análise de GONÇALVES (1996, p .1):

Se alguém, uma instituição, por exemplo, se propõe a desenvolver educação a distância, isto significa que esse alguém está preocupado com algo além da transmissão de informações ou do desenvolvimento de habilidades motoras e intelectuais. Seu compromisso é mais amplo: é com o desenvolvimento da cidadania [...] é com a igualdade de oportunidades de acesso ao saber acumulado pelo homem ao longo de sua história. Para ela, educar engloba o ensinar [...] não o elimina, como muitos acreditam.

Gonçalves ressalta, nesta análise, o papel social da educação a distância na igualdade de oportunidades e no desenvolvimento da cidadania. Esses dois pontos caracterizam a ação educativa. Além disso, o educar engloba o ensinar, vendo na educação a distância não só algo além do desenvolvimento das potencialidades intelectuais, mas também uma evolução no processo de participação do indivíduo no contexto social.

Os termos ensino e educação são considerados sinônimos na utilização textual de algumas definições, mas pode-se afirmar que o que estamos pesquisando é o que se define como educação a distância, porque a formação do aluno que utiliza-la não deve ser meramente técnica, mas, como a educação presencial, um processo de formação integral, somente diferenciando o espaço e tempo da aprendizagem que são substituídos por uma tecnologia.

Para alguns autores clássicos da educação a distância, ela se caracteriza, por exemplo em IBANEZ apud PRAVADELLI (1996), como estratégia em que não é imprescindível que o professor esteja junto ao aluno porque a didática tem um caráter múltiplo de ação. Esse caráter múltiplo é representado por diferenciações em relação ao método e à metodologia de trabalho que envolva alunos e professores.

Para CIRIGLIANO apud ARETIO (1987, p. 56):

Na educação a distância, excluído o contato direto entre educador e educando, é preciso que os conteúdos sejam tratados de um modo especial, isto é, tenham uma estrutura e organização que os tornem acessíveis ao aprendizado a distância. [...] O estudante a distância, ao tomar contato com o material estruturado, isto é, com os conteúdos organizados segundo determinado design, é como se, no texto ou no material estivesse em presença do próprio professor. 
A valorização do material para o estudo autônomo caracteriza-se pela explicação e melhor organização para que o aluno compreenda e saiba utilizálo sem nenhum problema, mas dificilmente o material impresso substituirá a relação professor-aluno e muito menos as trocas argumentativas e críticas num diálogo imediato de análises e interpretações.

De um lado, a valorização do aluno como responsável pelo seu aprendizado é essencial, mas, por outro, não se reduz exclusivamente ao aluno. $\mathrm{O}$ atendimento por um professor tutor (sua função é orientar o aluno, esclarecer dúvidas relativas ao estudo da disciplina pelo qual é responsável)e os meios pelos quais isso se desenvolverá são essenciais para o processo educacional.

Para HOLMBERG apud ALVES (1999, p. 15):

La educación a distancia cubre las distintas formas de estudio a todos los niveles, que no se encuentram bala la continua e immediata supervisión de los tutores presentes com sus estudiantes em el aula pero se benefician de la planificación, guía y seguimento de una organización tutorial.

Sus características son:

a) Se basa en comunicación no directa.

b) Se basa en cursos pre-producidos, autoinstructivos.

c) Se organiza la comunicación de ida y vuelta por medio de la palavra escrita.

d) Se tiene en cuenta el estudio individual.

e) Se estructura para llegar a grandes masas.

f) Se prepara los programas utilizando los métodos de trabajo industrial.

g) Se considera que está organizado como una forma mediatizada de conversación didáctica guiada. ${ }^{2}$

2 O termo educação a distância, para Homberg, cobre as diferentes formas de estudo em todo os níveis que não se encontram sob a contínua, imediata supervisão dos tutores presentes com seus estudantes em sala de aula, mas, sem dúvida, se beneficiam do planejamento, guia e seguimento de uma organização tutorial.

Suas características são:

a) Baseia-se em comunicação não direta.

b) Baseia-se em cursos pré-produzidos, auto-instrucionais.

c) Organiza-se a comunicação de ida e volta por meio da palavra escrita.

d) Valoriza-se o estudo individual.

e) São estruturados para chegar às grandes massas.

f) Os programas são preparados utilizando os métodos de trabalho industrial.

g) Considera-se que está organizado como uma forma mediatizada de conversação didática guiada. 
A definição de Holmberg considera vários tipos de metodologias de estudo via tecnologia para aqueles que não se encontram numa relação presencial com professores, ressaltando que é um tipo de educação para as grandes massas e adequada às perspectivas industriais. Expressa a educação a distância como uma forma direcionada de educação com o objetivo central ligado diretamente aos interesses do mundo do trabalho.

Enfim, todas as definições que caracterizam a educação a distância como facilidade de acesso e democratização do ensino estão inseridas nas perspectivas do mundo do trabalho. Portanto, no próximo item a discussão que realizaremos é o que denominamos demandas ocupacionais e como a educação a distância está inserida no processo de preparação desses recursos humanos na sociedade atual.

\section{Tendências e perspectivas para a educação a distância no mundo do trabalho}

Dentre as inúmeras análises que poderíamos realizar sobre as modificações do trabalho, o principal argumento aqui proposto é que o trabalho também passou nas últimas décadas por uma nova forma de valorização e estruturação.

Partindo dessa idéia, analisamos qual o significado do trabalho e sua denominação no processo atual de mutações econômicas, políticas e sociais. Segundo ANTUNES (1999, p. 15):

A década de 1980 presenciou-se, nos países de capitalismo avançado, profundas transformações no mundo do trabalho, nas suas formas de inserção na estrutura produtiva, nas formas de representação sindical e política. Foram tão intensas as modificações, que se pode mesmo afirmar que a classe-que-vive-do-trabalho sofreu a mais aguda crise deste século, que atingiu não só materialidade, mas teve profundas repercussões na sua subjetividade e, no íntimo inter-relacionamento destes níveis, afetou a sua forma de ser. 
Como expressa Antunes, as mudanças no conceito de trabalho atingiram não só as ações técnicas e intelectuais, mas a sua própria subjetividade, porque trouxeram novas formas de representação do trabalho para o ser humano, atribuindo às tecnologias uma outra perspectiva do trabalho, que passou por um momento de mudança de seus valores intrínsecos.

Sobre a mudança da sociedade do trabalho para a sociedade das tecnologias da informação e principalmente a mudança dos valores paradigmáticos, ressalta-se a importância no mundo dessas tecnologias que trouxeram o novo valor de paradigma denominado por CASTELLS (1999a) como informacional.

....o paradigma da tecnologia da informação é baseado na flexibilidade. Não apenas os processos são reversíveis, mas organizações e instituições podem ser modificadas, e até mesmo fundamentalmente alteradas, pela reorganização de seus componentes [...] a flexibilidade tanto pode ser uma força libertadora como também uma tendência repressiva, se os redefinidores das regras sempre forem os poderes constituídos... (CASTELLS, 1999a, p. 78)

A influência desse novo paradigma sobre as transformações do trabalho caracterizou nas últimas décadas os processos produtivos como sendo, segundo ANTUNES (1999): a flexibilização da produção, a especialização flexível, os novos padrões de busca de produtividade por novas formas de adequação da produção à lógica do mercado, a desconcentração industrial buscando novos padrões de gestão da força de trabalho e os direitos e conquistas dos trabalhadores substituídos e eliminados do mundo da produção.

Sobre a flexibilização, Ianni explicita em suas análises que:

O padrão flexível de organização da produção modifica as condições sociais e técnicas de organização do trabalho, torna o trabalhador polivalente, abre perspectivas de mobilidade social vertical e horizontal, acima e abaixo, mas também intensifica a tecnificação da força produtiva do trabalho, potenciando-a. $\mathrm{O}$ trabalhador é levado a ajustar-se às novas exigências da produção de mercadoria e excedente, lucro ou mais valia. Em última instância, o que comanda a flexibilização do trabalho e do trabalhador é um novo padrão de racionalidade do processo de reprodução ampliada do capital, lançado em escala global. (IANNI, 1996, p. 163) 
O desenvolvimento do trabalhador na caracterização da flexibilidade não apenas exige novos perfis de ação, mas toda uma reorganização de conhecimento e aplicabilidade desse conhecimento. Nesse aspecto é que a modificação no papel das escolas acontece nos seus valores, técnicas e modelos referenciados como corretos e necessários a determinada época do contexto social.

Segundo CORDENONSSI (1997, p. 146):

...quanto à flexibilidade, não há mais espaço para empresas de organização rígida, uma vez que a versatilidade da vida moderna coloca o homem e o mundo diante de mudanças diárias. Possuir sistemas empresariais flexíveis para atender, rapidamente, às mudanças de demanda do mercado e assim, continuar competindo, tornou-se essencial. O nível de exigência dessa flexibilidade se estende ao trabalhador, uma vez que ele é uma das unidades que movimenta a operação de produção. Assim, é imprescindível ter funcionários qualificados para atender às necessidades de flexibilidade empresarial.

A flexibilidade nas organizações empresariais tornou-se uma extensão à formação e ao perfil do trabalhador. Refletindo essa tendência, de acordo com ALVES (1997), a nova forma de produção, conhecida como "especialização flexível", apresenta três grandes características: as inovações tecnológicas trazidas pela informática, pela microeletrônica e pela descoberta de novos materiais, que possibilitaram um grande aumento da produtividade e a maior flexibilidade dos processos produtivos; posteriormente, as novas relações entre empresas desenvolvendo-se no que chamamos de terceirização, que consiste na tentativa de concentrar esforços naquelas atividades sobre as quais as empresas detêm vantagens competitivas, passando a adquirir serviços externos para realizarem essas atividades, descentralizando os trabalhos dessa área e, finalmente, como terceira característica tem-se o advento de novos processos organizacionais na produção e no trabalho interno das empresas que objetivam fundamentalmente o aumento da eficiência. Procura-se diminuir as hierarquias e possibilitar uma maior participação do trabalhador na gestão, exigindo-se assim aptidões individuais como autonomia e liderança para trabalhar em grupo, auxiliando no processo de desenvolvimento da organização e do próprio grupo. 
Esclarecendo melhor as argumentações, consideremos as análises de Pochmann $^{3}$, afirmando que existem atualmente quatro teorias que falam sobre as transformações do trabalho e do futuro do trabalho. As argumentações aqui realizadas consideram dois fatores para análise: tanto as diferenças de países desenvolvidos e em desenvolvimento, como a divisão de classes sociais por distribuição de renda.

A 1. ${ }^{a}$ teoria refere-se à redução do trabalho pela tecnologia. Esclarecendo essa afirmação, RIFKIN (1995, p. 3) pontua:

Agora, pela primeira vez, o trabalho humano está sendo sistematicamente eliminado do processo de produção [...]. Máquinas inteligentes estão substituindo seres humanos em incontáveis tarefas, forçando milhões de trabalhadores de escritório e operários para as filas do desemprego ou, pior, para as filas de auxílio do desemprego.

Segundo Pochmann, não há real comprovação de que a tecnologia cause a redução do trabalho. Para ele, o exemplo são os Estados Unidos e o Japão, com grandes tecnologias e sem modificação no aumento das taxas de desemprego. Já o que se observa no Brasil é exatamente o contrário: há a redução do trabalho porque as tecnologias não consomem o mesmo número de empregados em áreas de trabalho que substituiram as anteriormente realizadas; o índice de desemprego nessas condições, segundo dados empíricos, é alto.

Em segundo lugar, há a teoria do fim do emprego que é uma forma de trabalho com carteira assinada e um salário determinado. Pochmann analisa que a taxa das pessoas que têm algum tipo de salário nos Estados Unidos é de $89 \%$, contrapondo assim a tese de que o emprego está desaparecendo, mas o que observamos, especificamente no Brasil pelos meios de comunicação, é a crescente proporção de trabalhadores no mercado informal e sem carteira assinada.

A terceira teoria é a que trata da expansão do ócio criativo, ausência de trabalho explorado. Para Pochmann, o teórico dessa linha, o sociólogo italia-

3 Palestra proferida na Jornada do Curso de Economia, na Unesp, campus de Araraquara, 20 nov. 2000. 
no Domenico De Masi, não explica como se pode viver num país com menos trabalho se não houver formas de financiamento do tempo livre. Segundo De Masi:

O tempo sem trabalho ocupa um espaço cada vez mais central na vida humana. É preciso, então, reprojetar a família, a escola, a vida, em função não só do trabalho, mas também do tempo livre, de modo que ele não degenere em dissipação e agressividade, mas se resolva em convivência pacífica e ócio criativo. É preciso criar uma nova condição existencial em que estudo, trabalho, tempo livre e atividades voluntárias cada vez mais se entrelacem e se potencializem reciprocamente. (DE MASI, 1999, p. 25)

Nas condições brasileiras, o tempo livre é essencialmente preenchido com vários tipos de lazer para determinadas classes sociais. Em outras situações, especificamente para as classes menos privilegiadas, o que se observa são algumas ocupações para gerar algum tipo de renda.

A última teoria é o fim da chamada centralidade do trabalho, pela divisão internacional do trabalho. Segundo POCHMANN (2001), essa nova divisão pertence à dimensão financeira que compreende duas estruturações: a primeira associada ao processo de reestruturação empresarial, acompanhado da maturação de uma nova revolução tecnológica e a segunda está relacionada à expansão dos investimentos diretos no exterior, os quais, apesar do avanço no fluxo de recursos estrangeiros em países semiperiféricos permanecem fortemente centrados nas economias dos países desenvolvidos.

Paralelamente, ANTUNES (1999) afirma que :

Ao contrário daqueles autores que defendem a perda da centralidade da categoria trabalho na sociedade contemporânea, as tendências em curso, quer em direção à desqualificação ou à sua subproletarização, não permitem concluir pela perda desta centralidade no universo de uma sociedade produtora de mercadorias. Ainda que presenciando uma redução quantitativa (com repercussões qualitativas) no mundo produtivo, o trabalho abstrato cumpre seu papel decisivo na criação de valores de troca. (ANTUNES, 1999, p. 75) 
A perda da centralidade do trabalho não é decisiva em sua totalidade, pois com as novas tecnologias a própria exigência da competitividade e da produção aconteceram modificações e transformações pelas quais o trabalho abstrato ganhou maior espaço. $\mathrm{O}$ trabalho das empresas, com prioridade de força física, realmente perdeu um espaço grande nas atividades com as tecnologias, mas está sendo substituído pela modificação nas formas de realizar as tarefas dos trabalhos, que priorizam a qualificação, o treinamento e a capacitação da mão-de-obra para as tecnologias e para a qualidade do produto final.

Nas transformações do mundo do trabalho surge a segmentação do trabalho nas ocupações (trabalho informal, terceirizado, ocupações profissionais). Duas análises devem ser consideradas nesta segmentação: primeiramente a modificação da valorização desse trabalho enquanto capacidade criativa em gerar renda e, em segundo lugar, um trabalho voltado para o indivíduo e sua sobrevivência e não para a mais-valia do mercado.

O elo de ligação entre essas categorias de trabalho que é o eixo central definiu-se como a capacidade de gerar renda e produzir valores de troca por todos os tipos de trabalho de categorias formais ou informais, para movimentar o mercado de consumo.

Ainda segundo ANTUNES (2000, p. 9):

...em vez da substituição do trabalho pela ciência, ou ainda da substituição da produção de valores pela esfera comunicacional, da substituição da produção pela informação, o que se pode presenciar no mundo contemporâneo é uma maior inter-relação, uma maior interpenetração entre as atividades produtivas e improdutivas, entre as atividades fabris e as de serviços, entre atividades laborativas e as atividades de concepção, que se expandem no contexto da reestruturação produtiva do capital.

Nas análises de HIRATA (1996), pode-se afirmar que o trabalho no sentido assalariado perde a sua centralidade, na medida em que o volume de emprego assalariado regride e na medida em que o crescimento dos empregos precários e do desemprego de massa se dá internacionalmente.

$\mathrm{O}$ valor do trabalho, enquanto salário, passa a diferenciar quando realmente os níveis de contratos com salários fixos perdem para as rendas precárias e diferenciadas de acordo com ocupações no mundo do trabalho. 
Essas transformações nas relações sobre o trabalho e suas diferentes formas de manifestações influenciam diretamente no processo educativo. Para compreendermos essas transformações nos detivemos na análise sobre o mundo do trabalho e suas novas relações identificadas em sua segmentação a que denominamos demandas ocupacionais.

Segundo SINGER (1998, p. 14):

...na realidade, o que necessitamos é de ocupação e não de emprego. Ocupação compreende toda a atividade que proporciona sustento a quem a exerce. Emprego assalariado é um tipo de ocupação - nos países capitalistas o mais freqüente, mas não o único. Temos aqui outra generalização provavelmente enganadora. Como a falta de ocupação é chamada de "desemprego", pressupõe-se implicitamente que a única maneira de alguém ganhar a vida é vender sua capacidade de produção ao capital. ${ }^{4}$ Deixam-se de lado as múltiplas formas de atividade autônoma que, na realidade, estão crescendo no mundo inteiro e no Brasil, na medida mesma em que o capital contém seu ritmo de acumulação e tendencialmente reduz o volume de força de trabalho que emprega.

Ocupação aqui é entendida como a capacidade de gerar renda, ou seja, formas de trabalho que são trocadas por um valor econômico. Essas formas de trabalho têm vários níveis de categorias podendo ser intelectualizadas ou não. No âmbito legal e burocrático, as ocupações podem ou não ter vínculo empregatício; nesse sentido são uma forma de emprego em que o salário é a transferência de renda em troca da força de trabalho.

As discussões sobre as demandas ocupacionais são mais amplas porque se caracterizam pela necessidade de mão-de-obra, capital humano para funções e tarefas a serem realizadas tanto para trabalhadores da indústria (ocupações profissionais, entendidas como emprego) como para trabalhadores de serviços informais e terceirizados (aqui uma nova ótica de análise das demandas ocupacionais). Especificamente as demandas são caracterizadas como a necessidade de serviços associados com a capacidade de valor e troca. 
As demandas ocupacionais são segmentações no mundo do trabalho tanto em relação ao espaço (regiões) como em relação ao tempo (necessidades atuais). Dependem da necessidade das relações entre o mercado produtivo e tecnológico, numa dinâmica constante de aprimoramento e modificação. Num processo amplo de desenvolvimento, as necessidades são plurais e por isso as demandas ocupacionais se modificam nas suas ações, na forma e no próprio conteúdo de acordo com as regiões do país.

Para entendermos as novas demandas ocupacionais e conhecermos suas exigências precisamos considerar que os estudos tendem a fazer maior referência às perspectivas de expansão das ocupações profissionais que exigem maior escolaridade e qualificação profissional. Essas ocupações profissionais são diferenciadas nas tarefas e funções do trabalho realizado e se caracterizam como similar a sua profissão de origem, mas que na realidade dentro do paradigma da flexibilidade exigem outras competências e habilidades com maior ou menor qualificação.

Não se pode qualificar as ocupações profissionais somente como aquelas que exigem conhecimentos teóricos e práticos adquiridos num curso institucional, mas como uma qualificação que pode ser realizada em treinamentos, em capacitações em serviço ou em experiências apreendidas com os demais companheiros.

Entretanto, nas ocupações informais, pressupõe-se que o papel da educação formal em preparar o indivíduo com uma formação básica integrada aos seus conhecimentos tácitos permita sua adaptação às exigências e à flexibilidade do trabalho.

Portanto, o termo ocupação também é entendido como um conjunto de tarefas, operações e funções direcionadas aos trabalhadores, destinadas à obtenção de produtos ou serviços, passando a se caracterizar por habilidades e competências que se desenvolvem principalmente num perfil de ação diferente dos níveis intelectualizados de formação para as profissões em geral.

Baseando-se nas conceituações de BELLUZZO (1995), consideramos que nas ocupações as tarefas são atividades executadas por elementos que ocupam determinado trabalho. A função desses elementos é um conjunto de tarefas de um trabalho e a operacionalização é a ação do sujeito frente a essas tarefas com objetivos delimitados. Para a realização dessas ações é que são necessárias as competências e habilidades e o aprimoramento dos conhecimentos tácitos dos indivíduos, tanto intelectuais como de perfis pessoais.

Uma das características centrais da forma privilegiada de se priorizar a ocupação no sentido atual foi inicialmente a falta de empregos do setor industrial e o êxodo rural que, segundo POCHMANN (2001), têm sido contraba- 
lançados em parte pela evolução das ocupações ${ }^{5}$ no setor de serviços. A mudança ocorreu não só no trabalho que exige maior qualificação; as ocupações saíram da centralidade industrial e passaram a priorizar os setores de serviços.

Atualmente o setor de serviços passa por um crescente inchaço. Por causa disso, as alternativas de trabalho acabam ficando no setor informal que abrange as ocupações de serviços em geral.

Esses serviços são classificados, segundo Pochmann, em quatro classes ocupacionais:

A Distribuição, responsável principalmente pelas ocupações em comunicação, transporte e comércio; Produção, segmento moderno da sociedade pós-industrial que envolve as ocupações de atendimento dos insumos e serviços da produção (indústrias); Social, responsável pelas ocupações de atendimento ao consumo coletivo, como educação, segurança e saúde e a Pessoal, representada pelas ocupações de atendimento do consumo individual, como lazer, alimentos e embelezamento. (POCHMANN, 2001, p. 58)

Essas classes ocupacionais estão inseridas no que TEDESCO (1998) configura como estrutura ocupacional. Estão baseadas na existência de três categorias de trabalho: os serviços rotineiros, os serviços pessoais e os serviços simbólicos.

Como já nos referimos na introdução do presente trabalho, os serviços rotineiros implicam a execução de tarefas repetitivas; os serviços pessoais também supõem a realização de tarefas rotineiras e repetitivas, mas que não requerem muita educação e os serviços simbólicos são aqueles que se referem aos três grandes tipos de atividades que se realizam em empresas de alta tecnologia: identificação de problemas, solução de problemas e definição de estratégias.

Esses serviços se classificam por: qualificações profissionais e níveis educativos, além do tipo de formação básica e das habilidades e competências pessoais. Essas categorias de trabalho têm como centralidade as classes

5 Ocupação caracterizada como emprego. 
ocupacionais nas quais o trabalhador é classificado de acordo com os níveis de qualificação e as necessidades de produção do momento.

Para exemplificar melhor as argumentações, consideramos que, se na classe ocupacional denominada por Pochmann como distribuição, na qual estão inseridas as ocupações de comunicação, transporte e comércio, existisse uma pessoa que trabalhasse numa demanda de ocupação na área de comunicação, e essa mesma ocupação fosse caracterizada como informal e sem salário fixo, essa ocupação seria uma forma de trabalho que poderia ser categorizada como serviço pessoal, rotineiro ou simbólico, dependendo somente dos níveis educativos (competências e habilidades) da área em que se está realizando a ocupação.

Sintetizando as discussões realizadas sobre as demandas ocupacionais baseadas em: SINGER (1998), TEDESCO (1998) e POCHMANN (2001), organizamos um esquema de representação expresso na figura 1.

Entendendo o panorama do mundo do trabalho em suas peculiaridades e qualificações pertinentes, afirmamos que para as denominadas demandas ocupacionais, o fator educação está presente nas categorias de competências e habilidades a serem desenvolvidas nos recursos humanos. Para tanto, duas variáveis são pertinentes: o fator tempo e o custo.

A educação a distância, tanto via TV como internet, está presente como a solução e atendimento para essas demandas ocupacionais, em atualização, conhecimentos gerais; enfim a qualificação permanente da sociedade do conhecimento. 
FIGURA 1 - ESQUEMA DE REPRESENTAÇÃO SOBRE AS DISCUSSÕES DAS DEMANDAS OCUPACIONAIS.

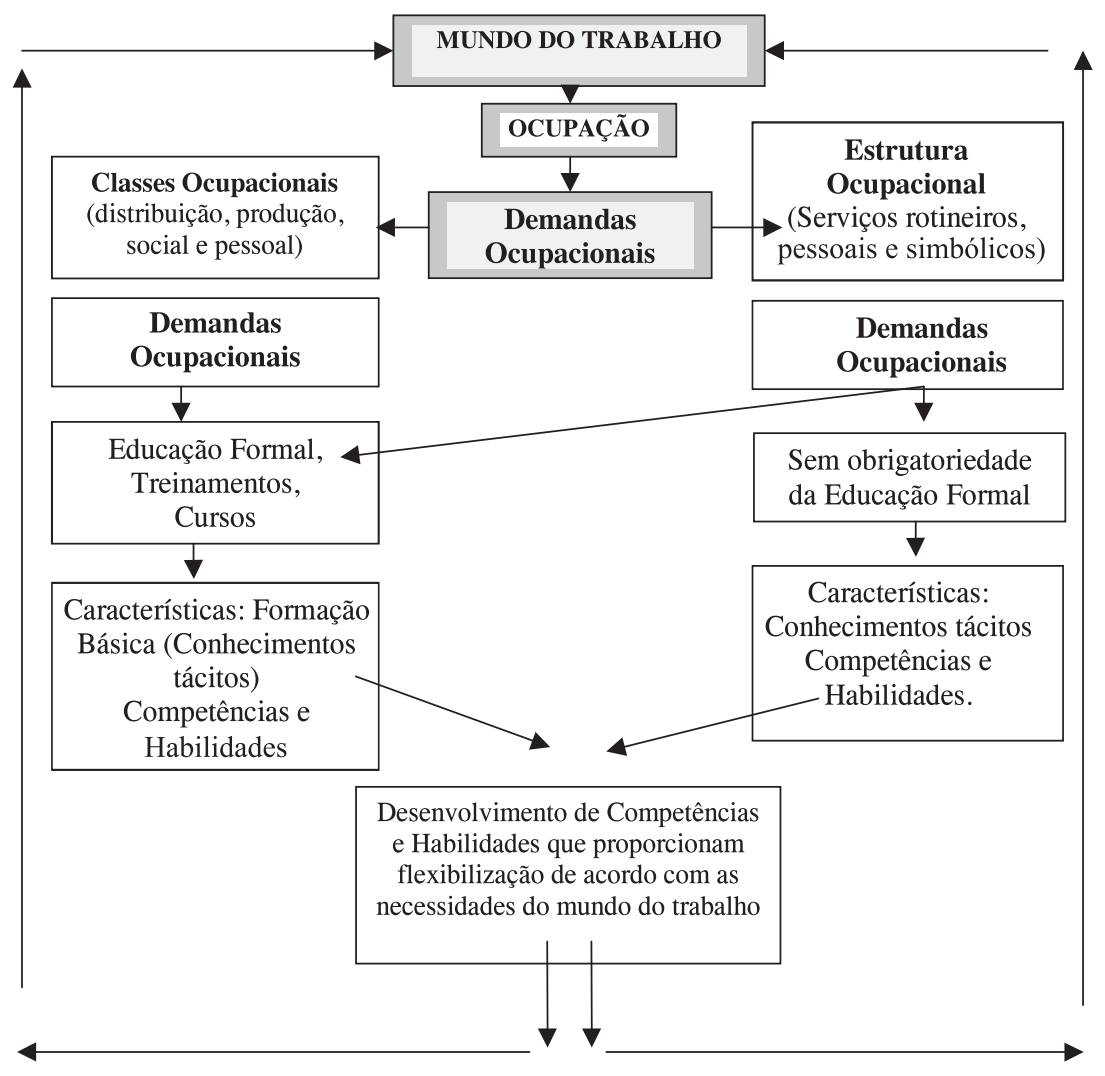

\section{REFERÊNCIAS}

ALVES, J. R. M. Recursos humanos para educação a distância. Rio de Janeiro: Instituto de Pesquisas Avançadas em Educação, 1999. 124 p.

ANTUNES, R. Adeus ao trabalho? Ensaio sobre as metamorfoses e a centralidade do mundo do trabalho. 6. ed. São Paulo: Cortez, 1999. 155 p.

ARETIO, L. G. Para uma definição de educação a distância. Tecnologia Educacional, Rio de Janeiro, v. 16, p. 56-61, set./dez. 1987. 
BELLONI, M. L. Educação a distância. Campinas: Autores Associados, 1999. 115 p. BELLUZZO, R. C. B. Da capacitação de recursos humanos à gestão da qualidade em Bibliotecas Universitárias: paradigma teórico prático para ambientes de serviço de referência de informação. São Paulo, 1995. Tese (Doutorado) - Departamento de Biblioteconomia e Documentação da Escola de Comunicação e Artes da Universidade de São Paulo.

BATES, A. W. T. Technology, decision-making and open and distance learning. In: . Technology, open Learning Distance Education. New York: Routhedge, 1995. p. 19-32.

BORDENAVE, J. E. D. Teleducação ou educação a distância: fundamentos e métodos. Petrópolis: Vozes, 1987. 77 p.

CASTELlS, M. A sociedade em rede. 3. ed. São Paulo: Paz e Terra, 1999. 617 p.

CHERMANN, M.; BONINI, L. M. Educação a distância: novas tecnologias em ambientes de aprendizagem pela internet. São Paulo: Universidade Braz Cubas, 2000. 80 p.

CORDENONSSI, A. M. Telecurso 2000: educação para o trabalho e para a cidadania. Impulso, p. 135-152, out. 1997.

DE MASI, D. O futuro do trabalho: fadiga e ócio na sociedade pós-industrial. Rio de Janeiro: J. Olympio, 1999. p. 11-27.

FIDALGO, F.; MACHADO, L. Dicionário da educação profissional. Belo Horizonte: Núcleo de Estudos Sobre o Trabalho e Educação, 2000. 414 p.

FROMM NETTO, S. Telas que ensinam: mídia e aprendizagem do cinema ao computador. Campinas: Alínea, 1998. 211 p.

GONÇALVES, C. T. F. Quem tem medo do ensino a distância. Educação a distância, n. 7-8. INED/IBASE. Disponível em: 〈http:/www. intelecto.net/ead/consuelo.html> Acesso em: maio 2000.

HIRATA, H. Competências e divisão social do trabalho no contexto de novos paradigmas produtivos. In: SEMINÁRIO INTERNACIONAL DE EDUCAÇÃO PROFISSIONAL, TRABALHO E COMPETÊNCIAS, 1996, Rio de Janeiro. Anais... Rio de Janeiro: [s.n.], 1996. p. 53-62.

IANNI, O. A era do globalismo. Rio de Janeiro: Civilização Brasileira, 1996. cap. 6, p. $153-187$.

NISKIER, A. Educação a distância: a tecnologia da esperança. São Paulo: Loyola, 1999. 414 p.

POCHAMANN, M. O emprego na globalização: a nova divisão internacional do trabalho e os caminhos que o Brasil escolheu. São Paulo: Boitempo, 2001. 151 p. 
PRAVADELLI, C. Educação a distância: pesquisa realizada em empresas que implantaram o Telecurso 2000. São Paulo, 1996. Dissertação (Mestrado) - Programa de Pós Graduação em Educação, Faculdade de Educação, Universidade de São Paulo.

RIFKIN, J. O fim dos empregos: o declínio inevitável dos níveis dos empregos e a redução da força global de trabalho. São Paulo: Makron, 1995. 348 p.

SINGER, P. Globalização e desemprego: diagnóstico e alternativas. São Paulo: Contexto, 1998. $139 \mathrm{p}$.

TEDESCO, J. C. O novo pacto educativo: educação, competitividade na sociedade moderna. São Paulo: Ática, 1998. p. 150.

Texto recebido em 20 jan. 2003

Texto aprovado em 20 de mar. 2003 